\title{
Learning receptive awareness via neurofeedback in stressed healthcare providers: a prospective pilot investigation
}

\author{
C. Michael Dunham ${ }^{1 *} \mathbb{D}$, Amanda L. Burger ${ }^{2}$, Barbara M. Hileman ${ }^{3}$ and Elisha A. Chance ${ }^{3}$
}

\begin{abstract}
Objective: Because physicians and nurses are commonly stressed, Bispectral Index ${ }^{\mathrm{TM}}$ (BIS) neurofeedback, following trainer instructions, was used to learn to lower the electroencephalography-derived BIS value, indicating that a state of receptive awareness (relaxed alertness) had been achieved.

Results: Ten physicians/nurses participated in 21 learning days with 9 undergoing $\leq 3$ days. The BIS-nadir for the 21 days was decreased (88.7) compared to baseline (97.0; $p<0.01$ ). From 21 wellbeing surveys, moderately-toextremely rated stress responses were a feeling of irritation 38.1\%; nervousness $14.3 \%$; over-reacting $28.6 \%$; tension 66.7\%; being overwhelmed 38.1\%; being drained 38.1\%; and people being too demanding $52.4 \%(57.1 \% \mathrm{had} \geq 2$ stress indicators). Quite a bit-to-extremely rated positive-affect responses were restful sleep 28.6\%; energetic 0\%; and alert $47.6 \%$ (90.5\% had $\geq 2$ positive-affect responses rated as slightly-to-moderately). For 1 subject who underwent 4 learning days, mean BIS was lower on day 4 (95.1) than on day 1 (96.8; $p<0.01)$. The wellbeing score increased $23.3 \%$ on day 4 (37) compared to day 1 (30). Changes in BIS values provide evidence that brainwave self-regulation can be learned and may manifest with wellbeing. These findings suggest that stress and impairments in positive-affect are common in physicians/nurses.
\end{abstract}

Trial Registration ClinicalTrials.gov NCT03152331. Registered May 15, 2017

Keywords: Bispectral Index, BIS monitor, Neurofeedback, Stress, Mindfulness, Physicians, Nurses

\section{Introduction}

For nurses and physicians, concerns exist relative to emotional exhaustion, burnout, and job dissatisfaction. Among medical students, residents/fellows, and early career physicians, adverse manifestation rates were $30-40 \%$ for emotional exhaustion, $40-50 \%$ for burnout, $40-60 \%$ for depression, $7-9 \%$ for suicidal ideation, and $50-60 \%$ for fatigue [1]. The rate of emotional exhaustion, a risk for burnout, is substantial in nurses in the United States $[2,3]$. Surveys have indicated that $20-35 \%$ of hospital-based nurses have expressed the intent to leave their current job in the near future $[2,4,5]$.

\footnotetext{
*Correspondence: dunham.michael@sbcglobal.net

1 Trauma, Critical Care, and General Surgery Services, St. Elizabeth Youngstown Hospital, 1044 Belmont Ave., Youngstown, OH 44501, USA Full list of author information is available at the end of the article
}

Mindfulness is an attitudinal expression of receptive awareness (relaxed attention), wherein there is a distinction made between a direct experience occurring in the present moment as opposed to associated thoughts and interpretations about the experience [6]. Among physicians and nurses, a high mindfulness score was associated with less stress, greater wellbeing, and a positive emotional tone [7, 8]. Mindfulness training has been associated with reductions in stress or burnout risk in nurses [9-11] and physicians [10-12].

Neurofeedback (NFB) is a process in which an individual learns to intentionally alter their brainwave activity [13]. NFB is useful for decreasing anxiety [14-16] and for enhancing attention [17, 18], mood [19], memory [20], musical performance [21], and surgical technique [22]. Sensors are applied and an electroencephalography (EEG) device computes the power according to 
frequency bandwidths [13]. A reward bandwidth target is chosen, typically an intermediate range [13, 23]. A computer monitor screen produces visual symbolic images as a mechanism for providing moment-to-moment EEG feedback to the trainee.

Although combining mindfulness and NFB has been advocated [24], such a model has not been evaluated. The purpose of our study was to evaluate a model of mindfulness and NFB to facilitate learning receptive awareness (relaxed attention). As concerns with EEG artifacts and the fact that technologies for providing quantitative EEG analysis are continuously evolving [25], we selected the Bispectral Index ${ }^{\text {TM }}$ (BIS) monitor (Aspect Medical Systems, Newton, MA) to provide NFB signals $[26,27]$. We hypothesized that receptive awareness or relaxed attention could be learned.

\section{Main text}

Physicians and nurses were welcomed to participate in the learning sessions. Each learning day consisted of two 12-min BIS monitor-NFB sessions. Immediately before session 1, specific instructions were given (Additional file 1). Immediately before session 2 , additional detailed instructions were provided (Additional file 2).

Using the manufacturer's instructions, the BIS sensor was applied to the participant's left forehead and temporal fossa following a scrubbing of the skin with alcohol and then wiping with a dry cloth. The BIS monitor chart data function was set to 1-min intervals such that the BIS value would be recorded on the monitor hard drive. Awake BIS values were available from the literature and included 685 subjects [28]. The first BIS value (minute 1) on learning day 1 of the first session was also used as a baseline reference for the learners.

A wellbeing surveillance tool was developed after reviewing elements from 5 established systems [29-33]. The physician/nurse learner completed the wellbeing surveillance tool before session 1 on each day. The 7 stress indicators included irritation, nervousness, over-reaction, tension, feeling overwhelmed, feeling emotionally drained, and feeling that people demand too much. The learner rated each indicator based on the prior 3 days as follows: (1) extremely; (2) quite a bit; (3) moderately; (4) a little; and (5) very slightly or not at all. The non-stress score was the sum of each indicator with a range of 7-35.

The 3 positive-affect indicators included restful sleep, feeling energetic, and feeling alert. The learner rated each indicator based on the prior 3 days as follows: (1) very slightly or not at all; (2) a little; (3) moderately; (4) quite a bit; and 5, extremely. The positive-affect score was the sum of each indicator with a range of 3-15. The total wellbeing score was the sum of the non-stress score and the positive-affect score with a range of $10-50$, such that a score of 10 suggested extreme stress and 50 suggested little to no stress (Additional file 3).

\section{Statistical analyses}

Data were entered into an Excel 2010 worksheet (Microsoft Corp., Redmond, WA, USA) and imported into the SAS System for Windows, release 9.2 (SAS Institute Inc., Cary, NC, USA). The level of significance was $p<0.05$. Summary group average values are presented as the mean and standard deviation.

\section{Results}

Ten physician/nurse subjects participated in 21 learning days (May to October 2017). The distribution of subjects according to the number of learning days was as follows: 1 day, 2 subjects; 2 days, 6 subjects, 3 days, 1 subject; and 4 days, 1 subject. The BIS-nadir for the 21 learning days was substantially lower $(88.7 \pm 3.2)$ than the awake values described in the literature $(96.6 \pm 1.7 ; p<0.0001)$. The BIS-nadir for the 21 learning days was also lower $(88.7 \pm 3.2)$ than the first BIS value on learning day 1 $(97.0 \pm 0.9 ; p<0.0001)$.

Of the 7 stress indicators, moderate-to-extremely responses were as follows: irritation, 8 learners (38.1\%); nervousness, 3 learners (14.3\%); over-reaction, 6 learners (28.6\%); tension, 14 learners (66.7\%); overwhelmed, 8 learners (38.1\%); drained, 8 learners (38.1\%); and people being too demanding, 11 learners (52.4\%). Of the 21 learning days, $17(71.4 \%)$ had at least 1 stress indicator and $12(57.1 \%)$ had $\geq 2$ stress indicators scored as moderately-to-extremely. Of the 3 positive-affect indicators, quite a bit-to-extremely responses were as follows: restful sleep, 6 learners (28.6\%); energetic, 0 learners $(0 \%)$; and alert, 10 learners (47.6\%). Of the 21 learning days, 19 (90.5\%) learners had $\geq 2$ positive-affects scored as very slightly or not at all-to-moderately. Summary results were as follows: total wellbeing score, $34.4 \pm 5.8$; non-stress score, $25.4 \pm 5.4$; and positive-affect score, $9.0 \pm 1.6$.

One subject underwent 4 learning days over a 19-day period. Mean BIS values were as follows: day 1, $96.8 \pm 1.4$; day 2, $96.4 \pm 1.7$; day $3,95.3 \pm 1.8$; and day $4,95.1 \pm 2.5$. Values were significantly different $(p<0.05)$ for day 1 compared to day 3 ; day 1 compared to day 4 ; day 2 compared to day 3; and day 2 compared to day 4 . The wellbeing score increased $23.3 \%$ on day 4 (37) compared to day 1 (30). The non-stress score increased $30.4 \%$ on day 4 (30) compared to day 1 (23).

\section{Discussion}

The lowest BIS value reached during the 21 learning day NFB sessions was substantially decreased, when compared to individuals described in the literature and to the very-first BIS value for each learner. These observations 
indicate that the learners were effectively able to alter their brainwave activity and enter an attentional state of receptive awareness or relaxed attention by following the instructions.

Data from the 21 wellbeing surveys demonstrated that stress was a common manifestation among the physiciannurse learners. That is, a substantial proportion of learners had perceptions of irritability, over-reaction, tension, feeling overwhelmed, feeling drained, or that people were too demanding. The mean non-stress score for the learners (25.4) represents a $30 \%$ reduction relative to the best non-stress score (35). This was an anticipated finding and it suggests that the newly developed surveillance tool may be useful.

Relative to the positive-affect indicators, a large percentage had perceptions that they were deficient in restful sleep, energy, or alertness. The mean positive-affect score for the learners (9.0) is a $40 \%$ reduction relative to an ideal positive-affect score (15). Such deficiencies are likely to be manifestations of stress. The mean total wellbeing score, sum of the non-stress and positive-affect scores, for the learners (34.4) represents a 30\% reduction relative to a perfect total wellbeing score (50).

Of substantial interest is the 1 learner who underwent 4 learning days. These data indicate that the ability to alter brainwave activity and enhance relaxed alertness is a progressively learned phenomenon. Similarly interesting was the increment in the total wellbeing and non-stress scores on learning day 4 when compared to day 1 . These data are consistent with the notion that learning receptive awareness (relaxed attention) might have an influence on daily wellbeing.

\section{Attentional focus and stress}

Immediately before session 1 , the learner was oriented to the BIS monitor screen and before session 2, the learner was told that they should not think too intensely or narrowly focus on the BIS number. Visual perceptual skills are largely influenced by attentional control which consists of executive, orienting, and alerting aspects [34]. Arousal, attention, and stress have an inverted U-shaped relationship with cognitive-motor performance, known as the Yerkes-Dodson law $[35,36]$. That is, performance is low with inadequate arousal, attention, and stress but increases with greater arousal, up to a level, where execution efficiencies then decrease with intense focus and excess stress.

Investigators have espoused that narrow attentional visual focus can increase anxiety, muscle tension, autonomic arousal, and hypervigilance [37-39]. Widening the visual scope of attentional focus has been associated with relaxed attention, a balanced state of arousal and sympathetic and parasympathetic neural function [38] and improvements in anxiety [37, 40,41] and athletic decision making [42]. Others have also provided evidence that enhancing one's awareness of external space positively increases intermediate brainwave activity [38, 39, 43], relaxation [44], and perceptions of wholeness [45, 46].

\section{BIS monitor}

The Food and Drug Administration classifies the BIS monitor as a computer device that detects EEG signals and may be used for assessing the clinical and physiological effects of anesthetic and sedating agents. The credibility and validity of the device is supported by more than 2500 citations in the National Library of Medicine that includes publications in the New England Journal of Medicine [47] and Cochrane Systematic Review [48]. Several studies have demonstrated significant associations between BIS monitor values (0-100) and clinical status, using the Modified Observer's Assessment of Alertness/ Sedation Scale, in patients undergoing general anesthesia $[49,50]$ or conscious sedation [51]. Reductions in BIS values have also been found for conditions other than pharmacologic sedation and include acupressure [52], stage I sleep [53], and relaxation using guided imagery [54]. For BIS values between 60 and 100, the level highlycorrelates $(\mathrm{r}=0.90 ; p<0.01)$ with the ratio of power in a brainwave band with high frequency $(30-47 \mathrm{~Hz}$ ) relative to an intermediate frequency band $(11-20 \mathrm{~Hz})$ [55]. That is, as the BIS value (the symbolic image being displayed) decreases, there is a relative linear reduction in the high frequency brainwave power relative to lower frequency brainwave power.

\section{Conclusions}

The BIS-nadir values provide objective evidence that the self-regulation of brainwave activity can be learned by altering attentional functions. The wellbeing surveys from the physician-nurse suggest that symptoms of stress were relatively frequent and punctuated with impairments in positive-affect. We are planning to provide participant compensation as a mechanism to incentivize learners to participate in at least 4 days of NFB to determine if learning receptive awareness is associated with improvement in wellbeing.

\section{Limitations}

The principal study limitation is that only 1 subject undertook 4 learning days of NFB. Thus, we cannot be certain that the decrease in BIS value and improvement in wellbeing over the 4 learning days will be replicated in a population of learners with similar participation. The wellbeing survey has not been validated using benchmark psychological testing. 


\section{Additional files}

Additional file 1. Specific instructions given before session 1.

Additional file 2. Pre-Session 1 Instructions. Specific instructions given before session 2 .

Additional file 3. Pre-Session 2 Instructions. Wellbeing surveillance tool and scoring system.

\section{Abbreviations}

BIS: Bispectral Index ${ }^{\mathrm{TM}}$; EEG: electroencephalography; NFB: neurofeedback.

\section{Authors' contributions}

$\mathrm{CMD}, \mathrm{AB}, \mathrm{BMH}$, and $\mathrm{EAC}$ conceptualized and designed the study. $\mathrm{BMH}$ and EAC instructed the learners and performed the Bispectral Index ${ }^{\mathrm{TM}}$ monitoring during the sessions. CMD performed the literature review and the data analysis. $C M D, A B, B M H$, and $E A C$ reviewed and interpreted the data, were involved in drafting the manuscript, and critically revised the manuscript for important intellectual content. All authors read and approved the final manuscript.

\section{Author details}

${ }^{1}$ Trauma, Critical Care, and General Surgery Services, St. Elizabeth Youngstown Hospital, 1044 Belmont Ave., Youngstown, OH 44501, USA. ${ }^{2}$ Behavioral Medicine, St. Elizabeth Family Medicine Residency, 1053 Belmont Ave., Youngstown, $\mathrm{OH} 44504$, USA. ${ }^{3}$ Trauma and Neuroscience Research Department, St. Elizabeth Youngstown Hospital, 1044 Belmont Ave., Youngstown, OH 44501, USA.

\section{Acknowledgements}

The authors wish to thank Marina C. Hanes, BA, ELS for copyediting the manuscript.

\section{Competing interests}

The authors declare that they have no competing interests.

\section{Availability of data and materials}

The datasets generated during and/or analyzed during the current study are not publicly available due to statutory provisions regarding data and privacy protection, but are available from the corresponding author on reasonable request.

\section{Consent for publication}

Not applicable.

\section{Ethics approval and consent to participate}

Mercy Health Youngstown Institutional Review Board for human investigations approved the project on April 19, 2017 (\#17-006). Written informed consent was required for study participation.

\section{Funding}

Mercy Health Foundation Mahoning Valley supplied the funding for the BIS sensors. The Foundation did not participate in the design of the study, data collection, data analysis, data interpretation, or writing the manuscript.

\section{Publisher's Note}

Springer Nature remains neutral with regard to jurisdictional claims in published maps and institutional affiliations.

\section{Received: 25 June 2018 Accepted: 31 August 2018}

Published online: 04 September 2018

\section{References}

1. Dyrbye LN, West CP, Satele D, Boone S, Tan L, Sloan J, et al. Burnout among U.S. medical students, residents, and early career physicians relative to the general U.S. population. Acad Med. 2014;89:443-51.

2. Vahey DC, Aiken LH, Sloane DM, Clarke SP, Vargas D. Nurse burnout and patient satisfaction. Med Care. 2004;42:1157-66.
3. Poghosyan L, Clarke SP, Finlayson M, Aiken LH. Nurse burnout and quality of care: cross-national investigation in six countries. Res Nurs Health. 2010:33:288-98.

4. Lindqvist R, Smeds Alenius L, Griffiths P, Runesdotter S, Tishelman C. Structural characteristics of hospitals and nurse-reported care quality, work environment, burnout and leaving intentions. J Nurs Manag. 2015;23:263-74.

5. Chang EM, Bidewell JW, Huntington AD, Daly J, Johnson A, Wilson H, et al. A survey of role stress, coping and health in Australian and New Zealand hospital nurses. Int J Nurs Stud. 2007;44:1354-62.

6. Perlman DM, Salomons TV, Davidson RJ, Lutz A. Differential effects on pain intensity and unpleasantness of two meditation practices. Emotion. 2010;10:65-71.

7. Atanes AC, Andreoni S, Hirayama MS, Montero-Marin J, Barros WV, Ronzani TM, et al. Mindfulness, perceived stress, and subjective well-being: a correlational study in primary care health professionals. BMC Complement Altern Med. 2015;15:303.

8. Beach MC, Roter D, Korthuis PT, Epstein RM, Sharp V, Ratanawongsa N, et al. A multicenter study of physician mindfulness and health care quality. Ann Fam Med. 2013;11:421-8.

9. Smith SA. Mindfulness-based stress reduction: an intervention to enhance the effectiveness of nurses' coping with work-related stress. Int J Nurs Knowl. 2014;25:119-30.

10. Goodman MJ, Schorling JB. A mindfulness course decreases burnout and improves well-being among healthcare providers. Int J Psychiatry Med. 2012;43:119-28.

11. Kemper KJ, Khirallah M. Acute effects of online mind-body skills training on resilience, mindfulness, and empathy. J Evid Based Complement Altern Med. 2015;20:247-53.

12. Regehr C, Glancy D, Pitts A, LeBlanc VR. Interventions to reduce the consequences of stress in physicians: a review and meta-analysis. J Nerv Ment Dis. 2014;202:353-9.

13. Marzbani H, Marateb HR, Mansourian M. Neurofeedback: a comprehensive review on system design, methodology and clinical applications. Basic Clin Neurosci. 2016;7:143-58.

14. Dias AM, van Deusen A. A new neurofeedback protocol for depression. Span J Psychol. 2011;14:374-84.

15. Cheon EJ, Koo BH, Seo WS, Lee JY, Choi JH, Song SH. Effects of neurofeedback on adult patients with psychiatric disorders in a naturalistic setting. Appl Psychophysiol Biofeedback. 2015:40:17-24.

16. Michael AJ, Krishnaswamy S, Mohamed J. An open label study of the use of EEG biofeedback using beta training to reduce anxiety for patients with cardiac events. Neuropsychiatr Dis Treat. 2005;1:357-63.

17. Egner T, Gruzelier JH. EEG biofeedback of low beta band components: frequency-specific effects on variables of attention and event-related brain potentials. Clin Neurophysiol. 2004;115:131-9.

18. Wang JR, Hsieh S. Neurofeed back training improves attention and working memory performance. Clin Neurophysiol. 2013;124:2406-20.

19. Raymond J, Varney C, Parkinson LA, Gruzelier JH. The effects of alpha/ theta neurofeedback on personality and mood. Brain Res Cogn Brain Res. 2005;23:287-92.

20. Escolano C, Aguilar M, Minguez J. EEG-based upper alpha neurofeedback training improves working memory performance. Conf Proc IEEE Eng Med Biol Soc. 2011;2011:2327-30.

21. Egner T, Gruzelier JH. Ecological validity of neurofeedback: modulation of slow wave EEG enhances musical performance. NeuroReport. 2003:14:1221-4.

22. Ros T, Moseley MJ, Bloom PA, Benjamin L, Parkinson LA, Gruzelier JH. Optimizing microsurgical skills with EEG neurofeedback. BMC Neurosci. 2009;10:87.

23. Gruzelier JH. Differential effects on mood of 12-15 (SMR) and 15-18 (beta1) Hz neurofeedback. Int J Psychophysiol. 2014;93:112-5.

24. Brandmeyer T, Delorme A. Meditation and neurofeedback. Front Psychol. 2013:4:688

25. Simkin DR, Thatcher RW, Lubar J. Quantitative EEG and neurofeedback in children and adolescents: anxiety disorders, depressive disorders, comorbid addiction and attention-deficit/hyperactivity disorder, and brain injury. Child Adolesc Psychiatr Clin N Am. 2014;23:427-64.

26. Nunes RR, Chaves IM, de Alencar JC, Franco SB, de Oliveira YG, de Menezes DG. Bispectral index and other processed parameters of electroencephalogram: an update. Rev Bras Anestesiol. 2012;62:105-17. 
27. Health Quality Ontario. Bispectral index monitor: an evidence-based analysis. Ont Health Technol Assess Ser 2004;4:1-70.

28. Dunham CM, McClain JV, Burger A. Comparison of Bispectral Index values during the flotation restricted environmental stimulation technique and results for stage I sleep: a prospective pilot investigation. BMC Res Notes. 2017; 10:640.

29. Osman A, Wong JL, Bagge CL, Freedenthal S, Gutierrez PM, Lozano G. The Depression Anxiety Stress Scales-21 (DASS-21): further examination of dimensions, scale reliability, and correlates. J Clin Psychol. 2012;68:1322-38.

30. Cohen S, Kamarck T, Mermelstein R. A global measure of perceived stress. J Health Soc Behav. 1983;24:385-96.

31. Watson D, Clark LA, Tellegen A. Development and validation of brief measures of positive and negative affect: the PANAS scales. J Pers Soc Psychol. 1988;54:1063-70.

32. Cappelleri JC, Bushmakin AG, McDermott AM, Dukes E, Sadosky A, Petrie $C D$, et al. Measurement properties of the Medical Outcomes Study Sleep Scale in patients with fibromyalgia. Sleep Med. 2009;10:766-70.

33. Maslach C, Leiter MP. Early predictors of job burnout and engagement. J Appl Psychol. 2008:93:498-512.

34. Fan J, Gu X, Guise KG, Liu X, Fossella J, Wang H, et al. Testing the behavioral interaction and integration of attentional networks. Brain Cogn. 2009;70:209-20.

35. Price JS. Evolutionary aspects of anxiety disorders. Dialogues Clin Neurosci. 2003;5:223-36.

36. Ghazali DA, Ragot S, Breque C, Guechi Y, Boureau-Voultoury A, Petitpas $F$, et al. Randomized controlled trial of multidisciplinary team stress and performance in immersive simulation for management of infant in shock: study protocol. Scand J Trauma Resusc Emerg Med. 2016;24:36.

37. Birnbaum MH. Nearpoint visual stress: clinical implications. J Am Optom Assoc. 1985:56:480-90.

38. Fehmi LG, Shor SB. Open focus attention training. Psychiatr Clin North Am. 2013;36:153-62.

39. Plotkin WB. On the self-regulation of the occipital alpha rhythm: control strategies, states of consciousness, and the role of physiological feedback. J Exp Psychol Gen. 1976;105:66-99.

40. Mortberg E, Hoffart A, Boecking B, Clark DM. Shifting the focus of one's attention mediates improvement in cognitive therapy for social anxiety disorder. Behav Cogn Psychother. 2015;43:63-73.

41. Brzezicka A, Krejtz I, von Hecker U, Laubrock J. Eye movement evidence for defocused attention in dysphoria-a perceptual span analysis. Int J Psychophysiol. 2012;85:129-33.
42. Ryu D, Abernethy B, Mann DL, Poolton JM, Gorman AD. The role of central and peripheral vision in expert decision making. Perception. 2013:42:591-607.

43. Hinterberger T, Schmidt S, Kamei T, Walach H. Decreased electrophysiological activity represents the conscious state of emptiness in meditation. Front Psychol. 2014;5:99.

44. Birnbaum MH. Holistic aspects of visual style: a hemispheric model with implications for vision therapy. J Am Optom Assoc. 1978;49:1133-41.

45. Cowling WR 3rd, Smith MC, Watson J. The power of wholeness, consciousness, and caring a dialogue on nursing science, art, and healing. ANS Adv Nurs Sci. 2008;31:E41-51.

46. Jonas-Simpson C. Awakening to space consciousness and timeless transcendent presence. Nurs Sci Q. 2010;23:195-200.

47. Avidan MS, Zhang L, Burnside BA, Finkel KJ, Searleman AC, Selvidge JA, et al. Anesthesia awareness and the bispectral index. N Engl J Med. 2008:358:1097-108.

48. Punjasawadwong Y. Bispectral index for improving anaesthetic delivery and postoperative recovery. Cochrane Database Syst Rev; 2014. http:// www.thecochranelibrary.com/. Accessed 10 June 2016.

49. Glass PS, Bloom M, Kearse L, Rosow C, Sebel P, Manberg P. Bispectra analysis measures sedation and memory effects of propofol, midazolam, isoflurane, and alfentanil in healthy volunteers. Anesthesiology. 1997;86:836-47.

50. Zhong T, Guo QL, Pang YD, Peng LF, Li CL. Comparative evaluation of the cerebral state index and the bispectral index during target-controlled infusion of propofol. Br J Anaesth. 2005;95:798-802.

51. Haberland CM, Baker S, Liu H. Bispectral index monitoring of sedation depth in pediatric dental patients. Anesth Prog. 2011;58:66-72.

52. Fassoulaki A, Paraskeva A, Kostopanagiotou G, Tsakalozou E, Markantonis S. Acupressure on the extra 1 acupoint: the effect on bispectral index, serum melatonin, plasma beta-endorphin, and stress. Anesth Analg. 2007;104:312-7.

53. Dahaba AA, Xue JX, Xu GX, Liu QH, Metzler H. Bilateral Bispectral Index (BIS)-Vista as a measure of physiologic sleep in sleep-deprived anesthesiologists. Minerva Anestesiol. 2011;77:388-93.

54. Hudetz JA, Hudetz AG, Reddy DM. Effect of relaxation on working memory and the Bispectral Index of the EEG. Psychol Rep. 2004;95:53-70.

55. Morimoto Y, Hagihira S, Koizumi Y, Ishida K, Matsumoto M, Sakabe T. The relationship between bispectral index and electroencephalographic parameters during isoflurane anesthesia. Anesth Analg. 2004;98:1336-40.
Ready to submit your research? Choose BMC and benefit from:

- fast, convenient online submission

- thorough peer review by experienced researchers in your field

- rapid publication on acceptance

- support for research data, including large and complex data types

- gold Open Access which fosters wider collaboration and increased citations

- maximum visibility for your research: over $100 \mathrm{M}$ website views per year

At BMC, research is always in progress.

Learn more biomedcentral.com/submissions 